\title{
La Granada en Florida: Una fruta de árbol para Florida?'
}

\author{
Ali Sarkhosh, Jeff Williamson; traducido por Eva Pabon²
}

- Nombre científico: Punica granatum L.

- Familia: Lythraceae

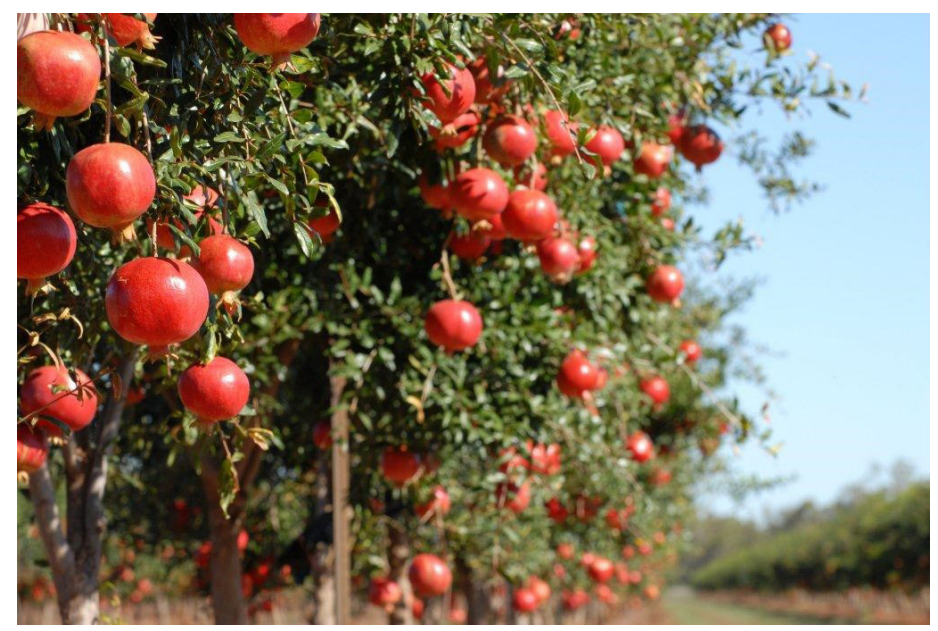

Figura 1. Árbol de granada ('Wonderful' cv.).

Crédito: Ali Sarkhosh, UF/IFAS

\section{Origen e Historia}

Las granadas son originarias de Asia central y se cultivaron en la antigua Persia, Babilonia, Egipto e India. Las granadas comunes se cultivaron por primera vez en Persia (hoy en día conocido como Irán) durante el año 3000 A.D. La granada fue cultivada extensamente en España, y llegaron a México y California con los misioneros en el siglo XVI.
El potencial económico en la producción comercial para el cultivo de granadas en Florida es actualmente desconocido.. La investigación científica continúa sobre la posibilidad de encontrar variedades de granadas que puedan crecer en Florida. Las condiciones ambientales, con una alta temporada húmeda en la Florida y un clima caluroso, son factores que son favorables para las enfermedades en las granadas y eso reduce la calidad de esta fruta, especialmente para las variedades de temporada tardía como la variedad 'Wonderful.' 'Wonderful' es el principal cultivar comercial que se originó en la Florida. Para reducir las enfermedades y evitar la competencia de comercialización con las granadas de California, la investigación para la producción de granadas en la Florida debe centrarse en buscar variedades de temporada temprana que puedan cosecharse en julio y agosto.

\section{Clima}

Las granadas se pueden cultivar desde climas templados hasta tropicales. Sin embargo, la mejor calidad de fruta de granada se produce en regiones con inviernos fríos y veranos calurosos y secos (clima mediterráneo). La granada es más resistente al frío que los cítricos. Sin embargo, los cultivares de granada varían en tolerancia a las temperaturas muy frías o heladas. En algunos casos, temperaturas por debajo de $12^{\circ} \mathrm{F}\left(-11^{\circ} \mathrm{C}\right)$ pueden dañar severamente árboles

1. Este documento, $\mathrm{HS1044,} \mathrm{es} \mathrm{uno} \mathrm{de} \mathrm{una} \mathrm{serie} \mathrm{de} \mathrm{publicaciones} \mathrm{del} \mathrm{Horticultural} \mathrm{Sciences,} \mathrm{Servicio} \mathrm{de} \mathrm{Extensión} \mathrm{Cooperativa} \mathrm{de} \mathrm{la} \mathrm{Florida,} \mathrm{Instituto} \mathrm{de}$ Alimentos y Ciencias Agrícolas, Universidad de la Florida (UF/IFAS Extension). Fecha de primera publicación: abril 2004. Revisado marzo 2015, octubre 2018, abril 2019. Visite nuestro sitio web EDIS en <http://edis.ifas.ufl.edu>. Traducido de la versión en inglés (HS44) al español en febrero de 2019 por Eva Pabon.

2. Ali Sarkhosh, profesor asistente y especialista en Extensión: Jeff Williamson, profesor, Departamento de Ciencias Hortícolas; UF/IFAS Extension, Gainesville, FL 32611. Traducido al Español por Rubén Regalado y C. F. Balerdi, Servicio de Extensión del condado Miami-Dade, Homestead, Florida.

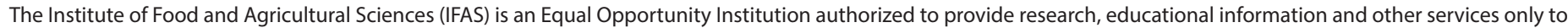

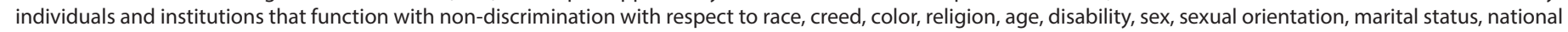
origin, political opinions or affiliations. For more information on obtaining other UF/IFAS Extension publications, contact your county's UF/IFAS Extension office. 
que están hibernando (Figura 2); árboles que no están hibernando pueden dañarse con temperaturas más altas de $28^{\circ} \mathrm{F}\left(-2^{\circ} \mathrm{C}\right.$, Figura 3$)$. Varios miles de acres se cultivan en California y algunos productores están llevando a cabo pruebas regionales con diferentes variedades en Florida, Georgia, Arizona, Texas y otros estados en los EE. UU.

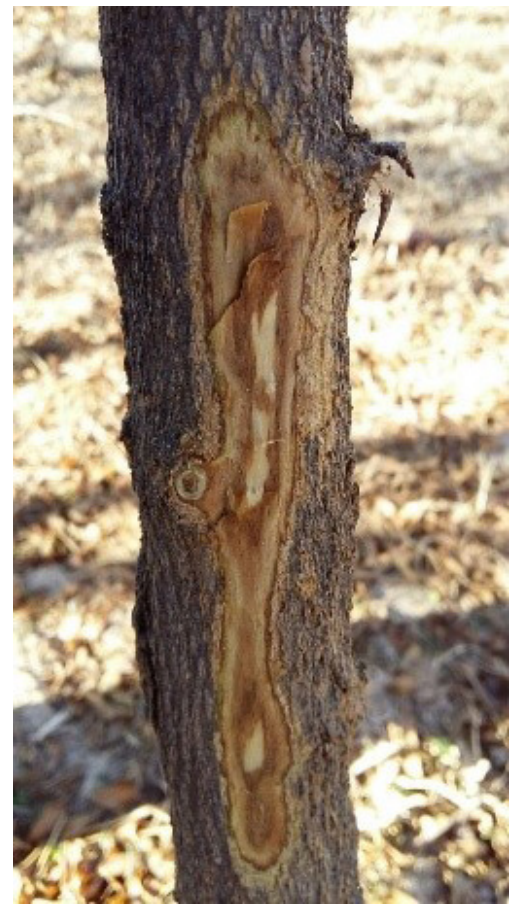

Figura 2. Daño por congelación $\left(12^{\circ} \mathrm{F}\right)$ a un árbol que esta hibernando. Crédito: Ali Sarkhosh, UF/IFAS

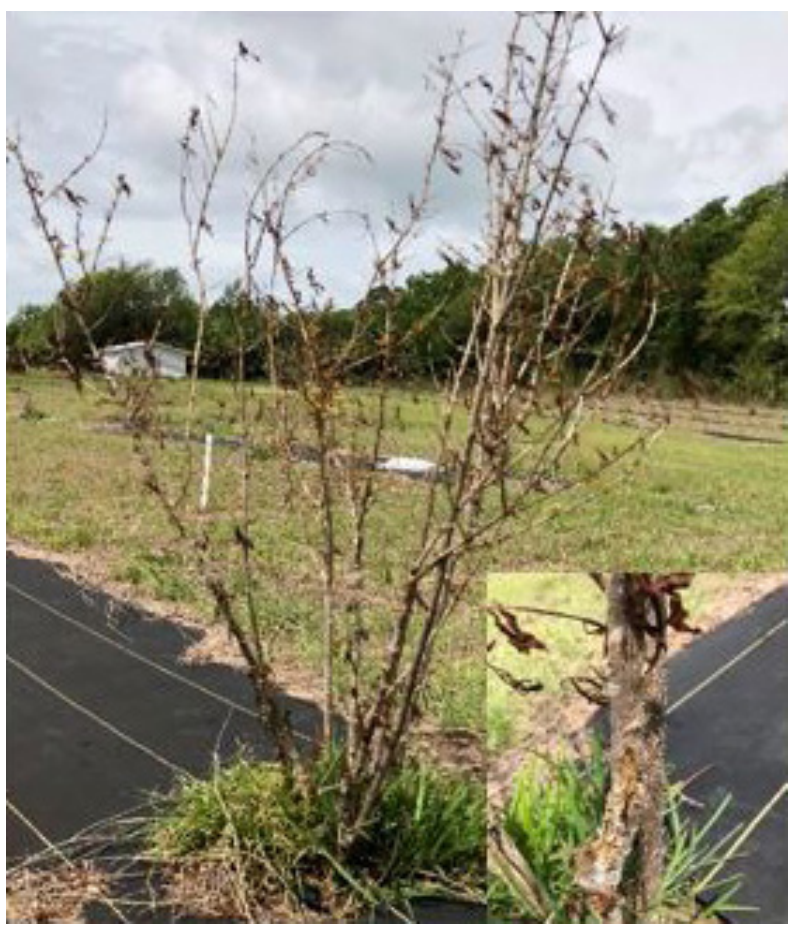

Figura 3. Daño por congelación $\left(12^{\circ} \mathrm{F}\right)$ a un árbol que esta hibernando. Crédito: Ali Sarkhosh, UF/IFAS

\section{Descripcion}

Normalmente es un arbusto denso y deciduo, puede alcanzar una altura de $6-12$ pies $(2-4 \mathrm{~m})$, la planta tiene ramas finas y espinosas. Puede ser podado como un árbol pequeño que alcanza $12-20$ pies $(4-7 \mathrm{~m})$ de altura (Figura $4)$.

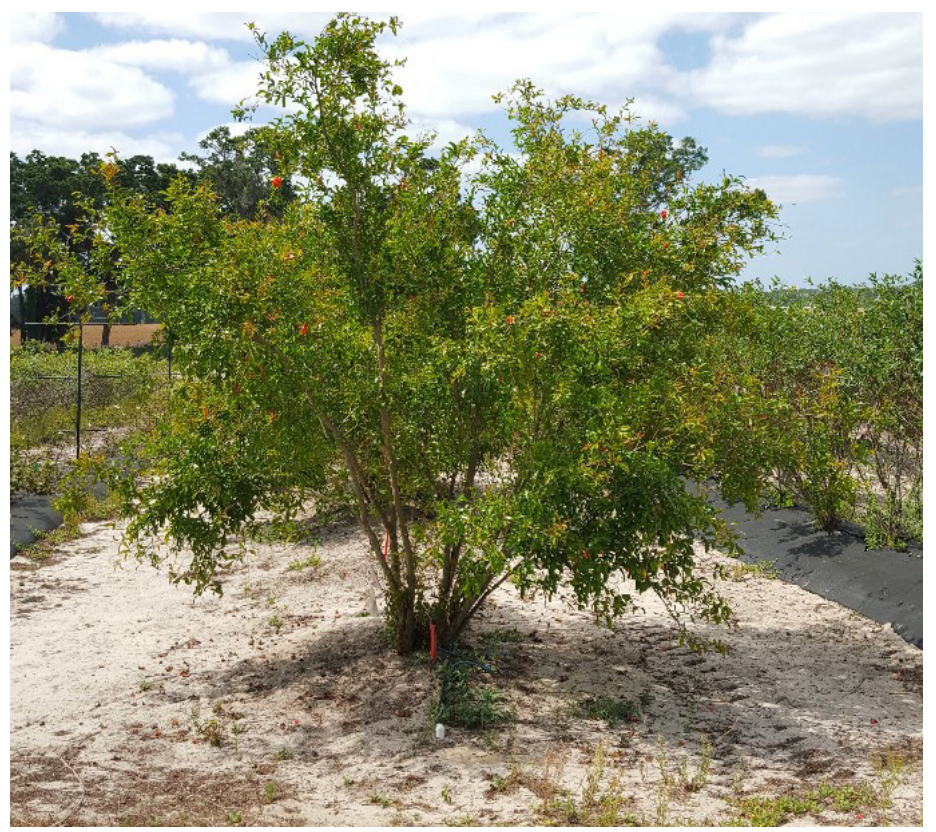

Figura 4. Árbol de granada cultivado como multi-tronco. Crédito: Ali Sarkhosh, UF/IFAS

La granada es una planta ornamental atractiva y hay algunas variedades disponibles para fines ornamentales, estás no producen fruta (Figura 5).

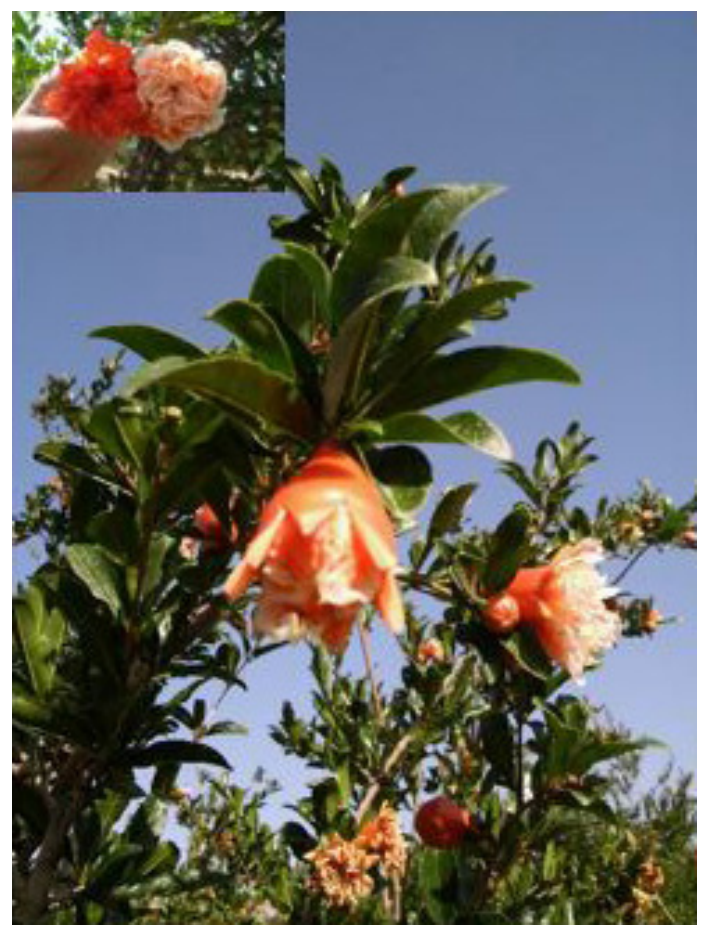

Figura 5. Granada ornamental.

Crédito: A. Yavari 
Las hojas de granada son brillantes, de color verde oscuro, la forma de la hoja es oblonga a ovalada, de 1-1.25 ft (2.5-3 $\mathrm{cm})$ de largo. Las hojas se organizan opuestas y los pares se cruzan alternativamente en ángulos rectos y se agrupan en ramillas cortas (Figura 6).

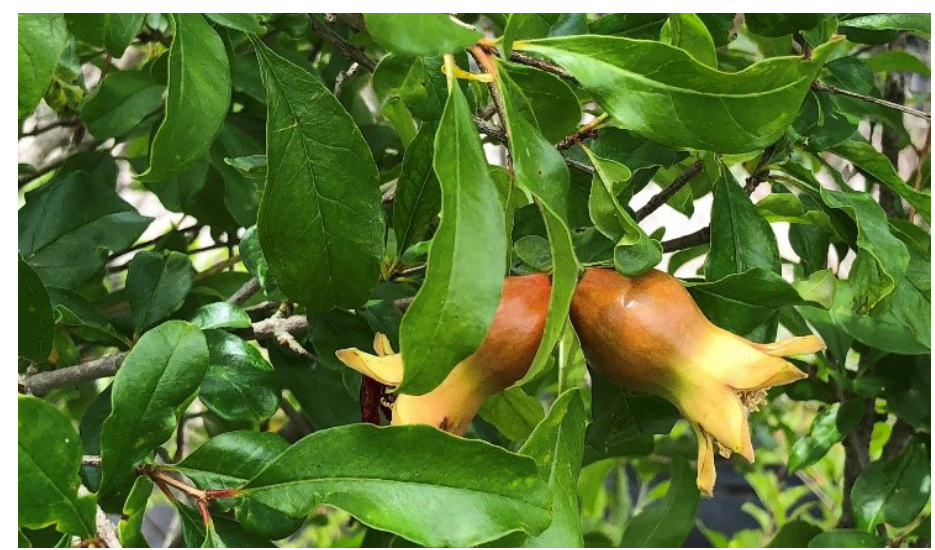

Figura 6. Hojas de granada y fruta joven.

Crédito: A. Sarkhosh, UF/IFAS

Las flores son de color rojo-anaranjado brillante, de 1.5-2.5 in $(4-6 \mathrm{~cm})$ de diámetro con pétalos arrugados y numerosos estambres. Las flores nacen solitarias o en pequeños racimos en ángulo hacia el final de las ramillas. Las flores son "perfectas", contienen partes masculinas y femeninas, sin embargo, los árboles de granada generalmente llevan dos tipos de flores; es decir, femenino (produce fruta, Figura 7), masculino (no produce fruta, Figura 8). En las flores masculinas, los pistilos no se desarrollan como en las flores femeninas y no producen fruto. Las flores generalmente son auto polinizadas.

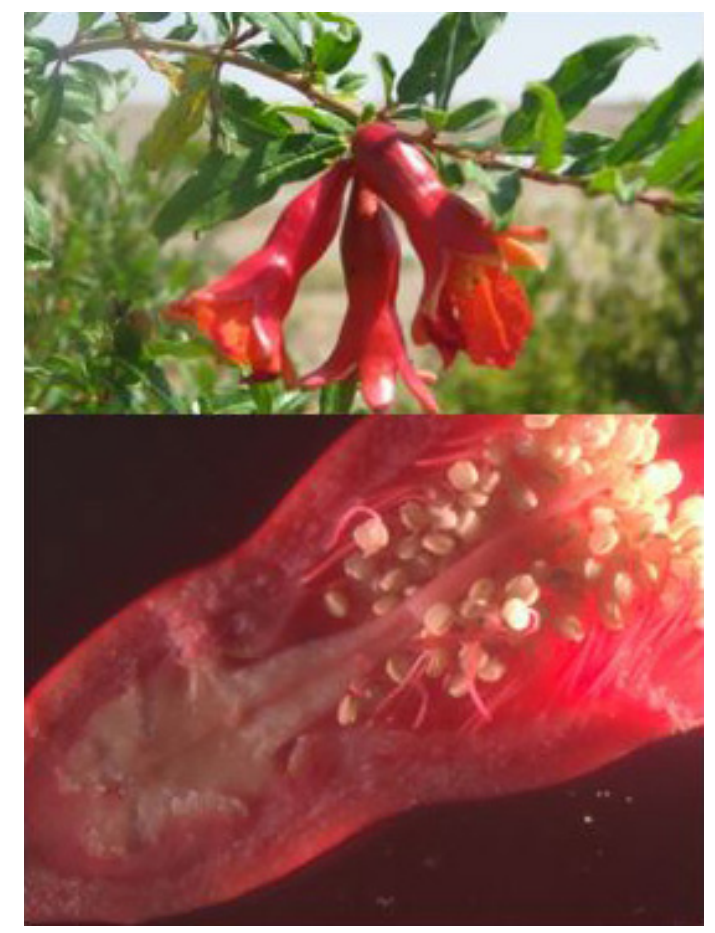

Figura 7. Flor femenina (flor que produce fruto). Crédito: A. Sarkhosh, UF/IFAS

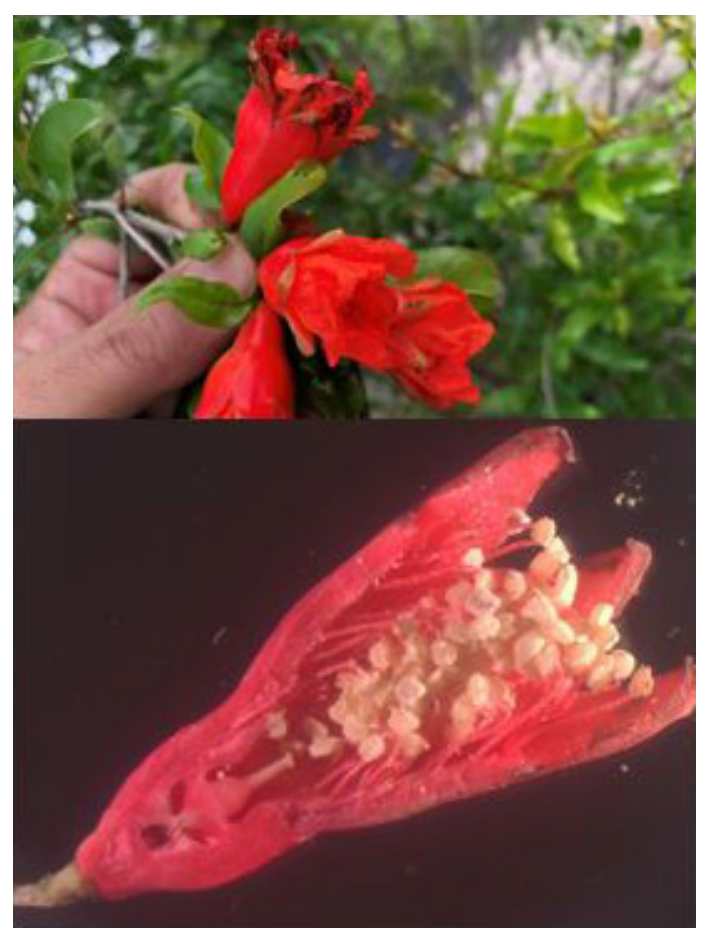

Figura 8. Flor masculina (flor que no produce fruto).

Crédito: A. Sarkhosh, UF/IFAS

\section{Cultivares}

El cultivar 'Wonderful' (Figura 9) se cultiva comercialmente en California, pero los esquejen proviene de Florida. La temporada húmeda y el clima caloroso de la Florida, son factores que reducen la calidad de las frutas de maduración tardía, como 'Wonderful'. Por lo tanto, la variedad 'Wonderful' no es un cultivar adecuado para Florida. Además, los cultivares de maduración temprana que maduran en julio y agosto, en Florida, evitarán la competencia de las granadas comerciales de California. Sin embargo, en este momento, el potencial económico para cultivar el árbol de granada comercialmente en Florida es desconocido.

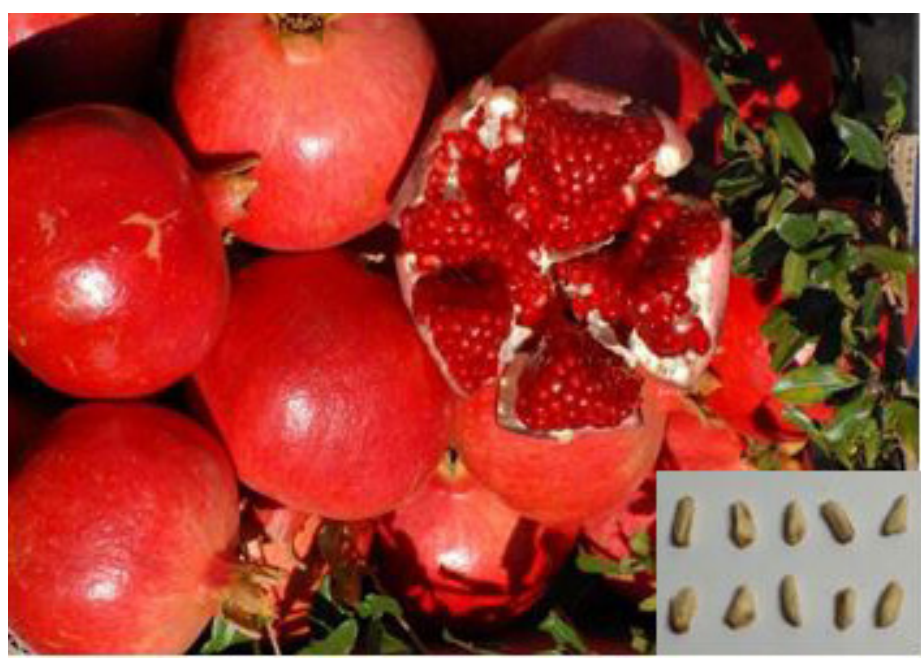

Figura 9. Fruta de granada, arilo y semilla.

Crédito: A. Sarkhosh, UF/IFAS 
Hay muchas variedades de granadas con diferentes características de frutas que se cultivan en Florida. La investigación continúa sobre la posibilidad de encontrar cultivares de granada que puedan crecer en Florida (Figura 10). Hoy en día, la granada se puede comprar en algunos supermercados no solo como frutas y jugos enteros, sino también como arilos envasados. Se ha desarrollado una máquina automática de extracción de arilo con la capacidad de extraer aril de 100 toneladas de granada por día. Existe la posibilidad de que diferentes variedades de granada con diferentes colores de aril puedan comercializarse en el futuro. Sin embargo, se necesitan más estudios y pruebas sensoriales sobre las características de las frutas de las variedades cultivadas en Florida. Las evaluaciones iniciales de algunas variedades de granada indican que las variedades que no producen fruta con buena forma, tamaño y apariencia en Florida podrían ser adecuadas para arilo o jugo envasados (Figura 11). Las enfermedades que se desarrollan durante la temporada de cultivo y el clima caliente / húmedo de la Florida reducen la calidad de la fruta y continúan siendo una gran limitación para la producción.

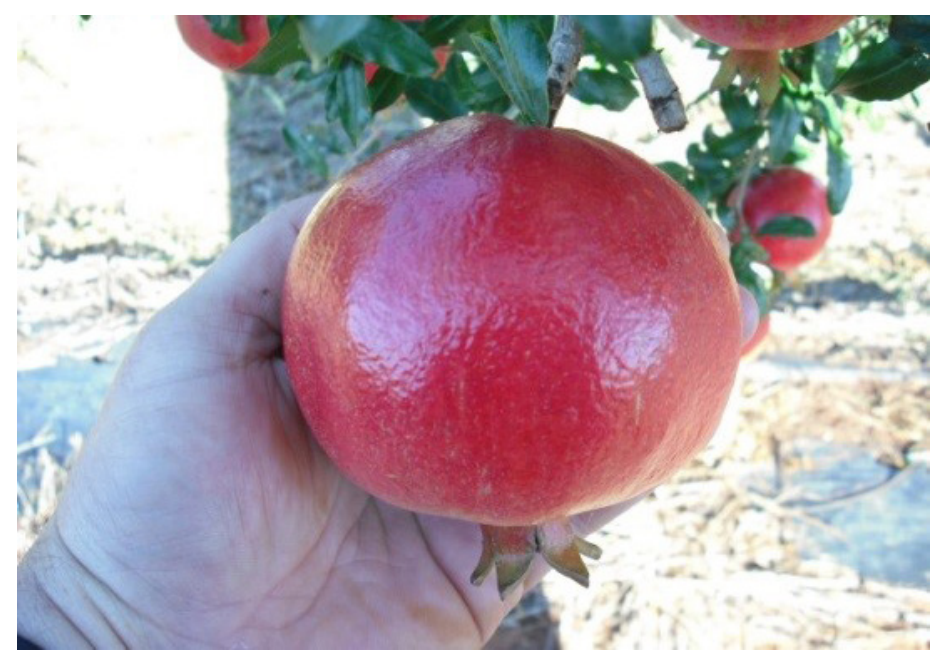

Figura 10. Cultivar 'Wonderful'.

Crédito: A. Sarkhosh, UF/IFAS

\section{Propagación}

Los árboles se propagan más fácil utilizando esquejes de madera dura durante el invierno, estos deben ser de 6-8 pulgadas $(15-20 \mathrm{~cm})$ de largo y del grosor de un lápiz o más ancho de diámetro (Figura 12). En Florida, los esquejes de madera dura deben tomarse en enero o febrero y colocarse verticalmente en el suelo con los 2-4 nodos superiores expuestos. Los esquejes pueden dejarse en hileras de vivero durante 1 o 2 años. Las plantas propagadas por semillas puede que no sean idénticas a la fruta, pero las semillas germinarán en 45-60 días. El acodo también es exitoso, pero requiere más mano de obra.

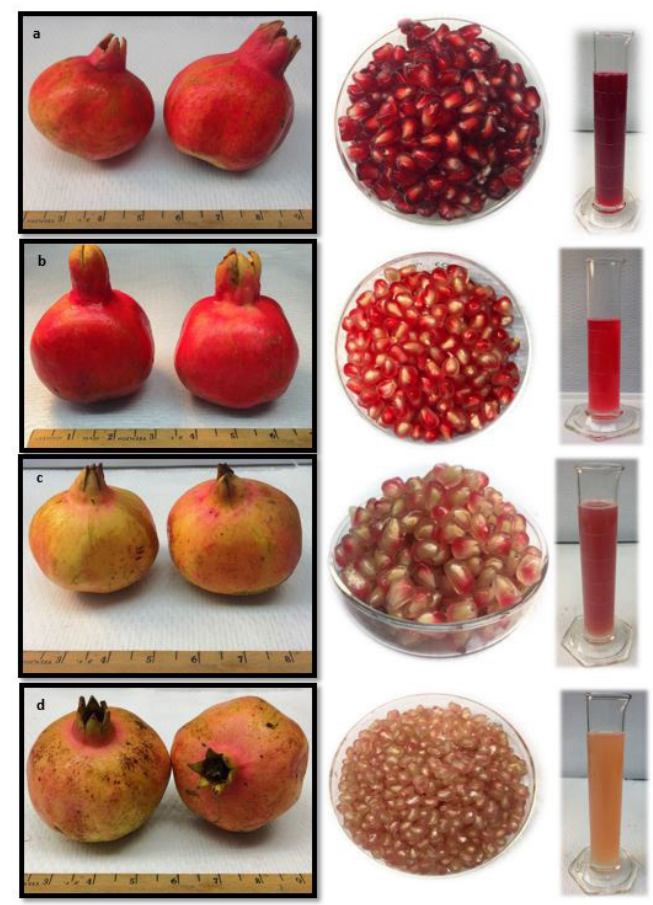

Figura 11. Características de fruto, semillas y zumos de algunas variedades de granadas cultivadas localmente en Florida, cosechadas en agosto de 2018; a) 'Vkusnyi' b) 'Crab' c) 'Mack Glass' d) 'Ever Sweet'. Crédito: A. Sarkhosh, UF/IFAS

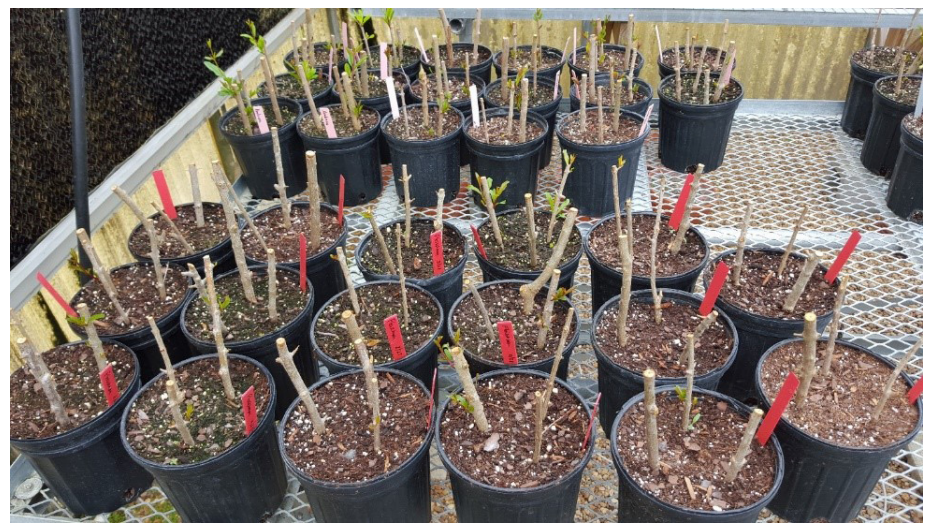

Figura 12. Propagación de esqueje.

Crédito: A. Sarkhosh, UF/IFAS

\section{Suelos}

Las granadas producen mejor en suelos francos profundos, pero se pueden adaptar a muchos tipos de suelos, desde arena pura hasta arcilla pesada. El rendimiento suele ser bajo en arena, mientras que el color de la fruta es pobre en arcillas. El crecimiento en suelos alcalinos es pobre. El crecimiento óptimo se asocia con suelos bien drenados, no pesados o húmedos en el rango de $\mathrm{pH}$ de 5.5-7.0.

\section{Irrigación}

Los requisitos de agua para la granada son aproximadamente los mismos que para los cítricos: 50-60 pulgadas $(125-150 \mathrm{~cm})$ por año. Los árboles deben ser irrigados cada 7-10 días en ausencia de lluvias significativas. Durante 
la maduración de la fruta generalmente se recomienda reducir el riego gradualmente para reducir las fracturas, pero también para mejorar el desarrollo del sabor y el color. Las lluvias de verano pueden ser un problema en algunas partes de Florida. Los cambios repentinos en la cantidad y el tiempo de riego a menudo conducen a la división de la fruta, especialmente unas semanas antes de la cosecha. Mantenga una humedad adecuada del suelo a finales del verano y principios del otoño para reducir la posible división de la fruta. Las granadas son tolerantes a algunas inundaciones.

\section{Sembrado y distancia entre plantas}

Plante árboles a comienzos de primavera (febrero-marzo), evitando las heladas tardías. El suelo debe ser trabajado y no mojado. Cuando se usan como un seto vivo, las plantas se siembran a 6-9 pies (2-3 m) de distancia.

Los retoños llenarán espacios y producirán un seto vivo compacto. La distancia de siembra de $10-16$ pies (3-5 m) entre las plantas y 13-20 pies (4-6 m) entre las hileras se usa para los huertos, y se debe mantener una distancia de siembra similar para los árboles de jardin en la casa (Figura 13).

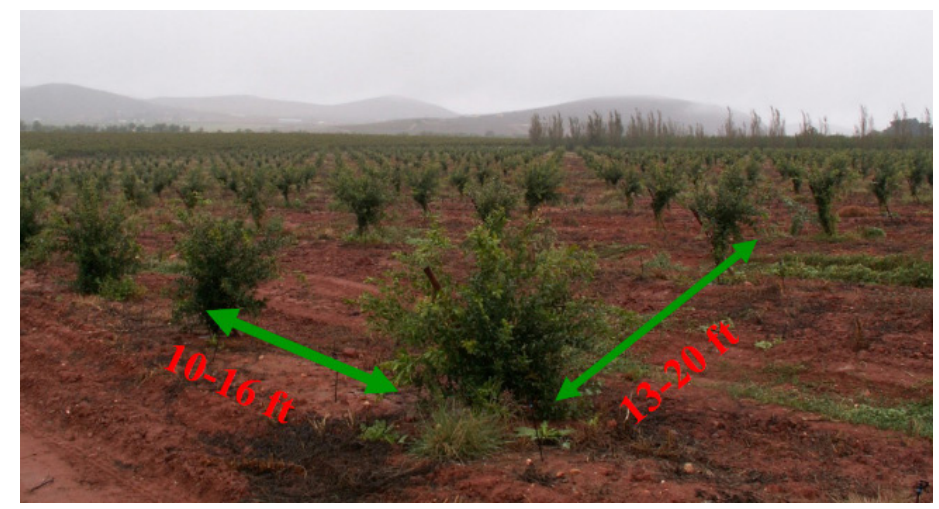

Figura 13. Espacio entre árboles.

Crédito: A. Sarkhosh, UF/IFAS

\section{Entrenamiento y poda}

Los árboles que poseen hábitos de crecimiento arbustivo tupido tienden a generar muchos retoños o puntos de crecimiento desde la raíz hasta la corona. Para propósitos de producción comercial estos árboles deben entrenarse a través de la poda para que solo se desarrolle un pequeño grupo de tronco o un tronco (Figura 14). Aquellos retoños adicionales que crecen cerca del tronco o troncos principal (es) deben eliminarse. Durante los primeros dos años, la poda promueve una forma robusta y compacta de crecimiento. Al momento de la siembra, los árboles se deben cortar o podar a $2-2.5$ pies $(60-75 \mathrm{~cm})$ y desarrollar de tres a cinco ramas simétricamente esparcidas para promover el crecimiento de nuevos brotes. Estos brotes no deben llegar a menos de $12(20-25 \mathrm{~cm})$ pulgadas del suelo. Corte las ramas a 3/5 de su longitud durante el invierno después de la siembra. Elimine las ramas y brotes que interfieran dejando dos o tres brotes por rama tipo andamio.

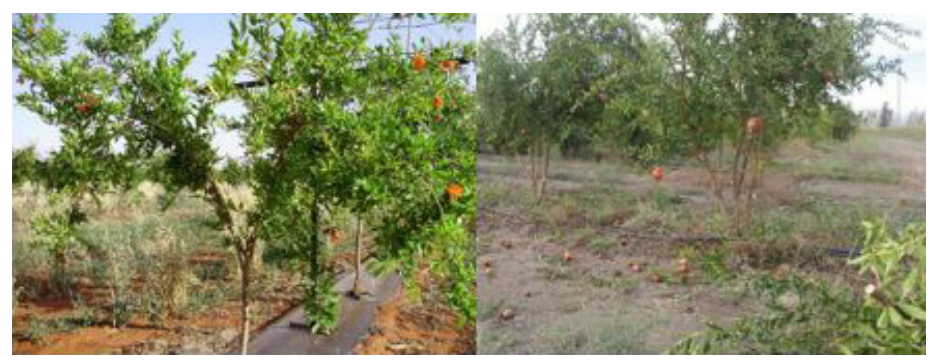

Figura 14. Sistema de entrenamiento, izquierda: un solo tronco, derecha: múltiples troncos.

Crédito: A. Sarkhosh, UF/IFAS

Las ramas que dan fruto se doblarán o romperán por el exceso de fruto a menos que se practique el aclareo de la fruta o se realice una poda para reducir la carga de la cosecha. La fruta que toque el suelo se pudrirá o se dañará por plagas (Figura 15).

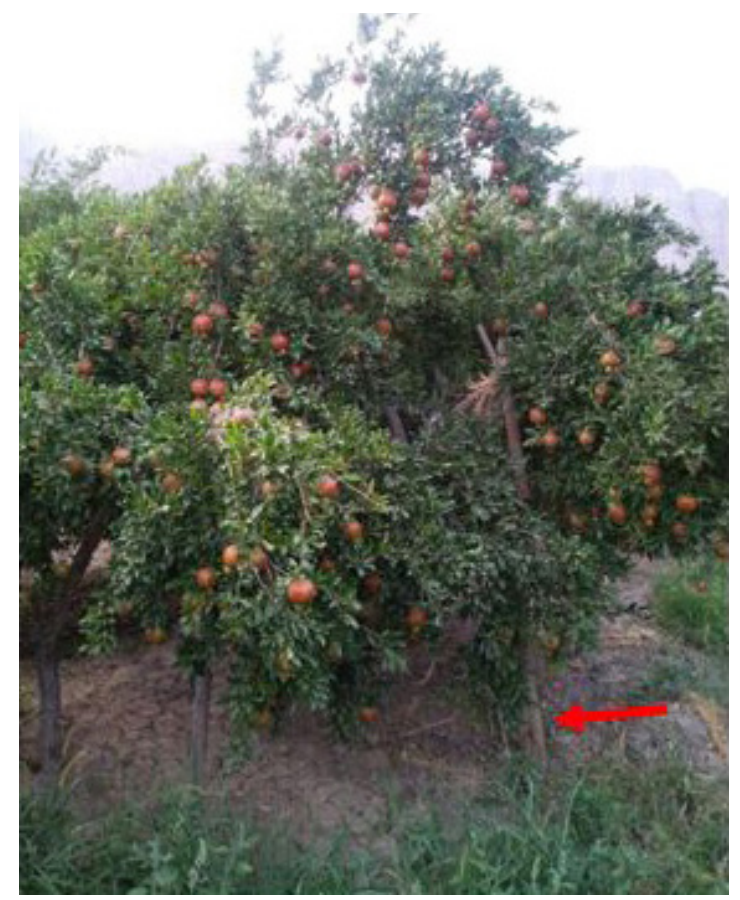

Figura 15. Se muestra el soporte provisto al árbol de granada para mantener la fructificación fuerte.

Crédito: A. Sarkhosh, UF/IFAS

\section{Consideraciones Especiales}

Los árboles de granada se auto polinizan. La caída severa de fruta durante el período juvenil de la planta (3-5 años) es normal. La caída de la fruta aumenta por prácticas que inducen el crecimiento vegetativo, como la fertilización excesiva y el riego excesivo. Evite poner árboles jóvenes en 
condiciones estresantes. La caída de fruta es menos severa en árboles maduros que en árboles más jóvenes.

\section{Enfermedad}

La enfermedad más destructiva observada en Florida es la antracnosis causada por un hongo del genero Colletotrichum sp (Figura 16). La enfermedad puede afectar las hojas, los tallos, las flores y la fruta. Los síntomas en la hoja incluyen áreas circulares a angulares pequeñas, oscuras, de color marrón rojizo a negro, de un tamaño de 0,25 pulgadas (4-5 mm) de diámetro. Las hojas infectadas son de color verde pálido y se caen prematuramente. Los síntomas en la fruta son manchas pequeñas, conspicuas, de color marrón oscuro, inicialmente circulares, que se vuelven irregulares. Para prevenir esta enfermedad se recomienda tres aplicaciones de fungicida de cobre neutral para reducir el impacto de la enfermedad.

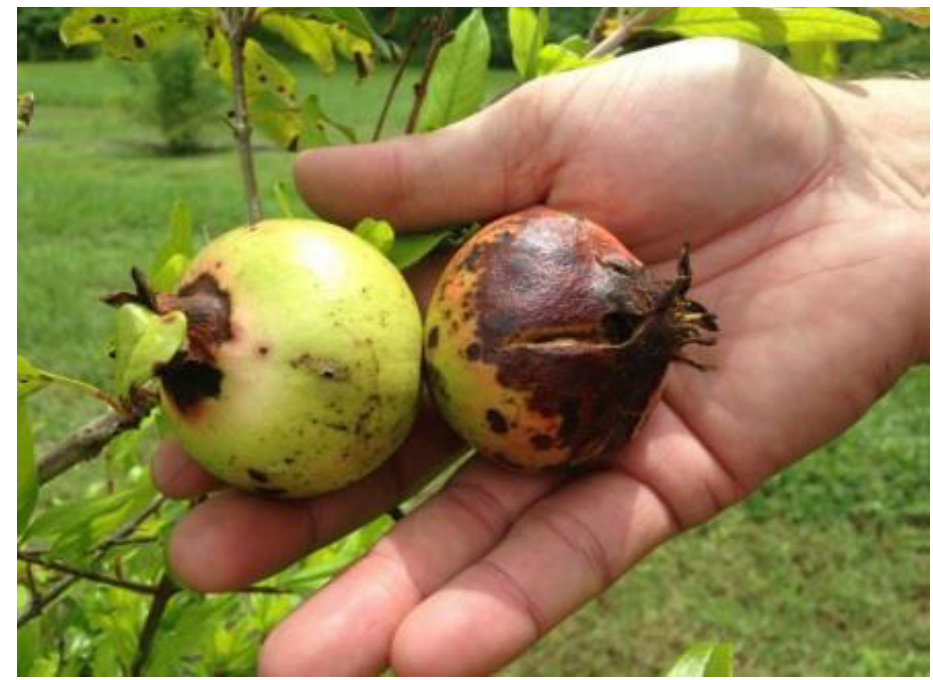

Figura 16. Daño de la antracnosis causado por Colletotrichum sp en la fruta de la granada.

Crédito: G. Vallad, UF/IFAS

\section{Insectos}

Queresas y ácaros ocasionalmente atacan la planta, pero estos hacen poco daño. El polvo de azufre aplicado a principios de junio ofrece un buen control de los ácaros. Las cochinillas pueden controlarse con una aplicación de aceite hortícola al 3\% durante el invierno cuando las hojas no están presentes. Los barrenadores de árboles también pueden infestar y matar árboles (Figura 17).

El Dr. Bill Castle, profesor emérito del Departamento de Ciencias Hortícolas de IFAS, de la Universidad de Florida ha desarrollado un sitio web de granada para Florida, http://www.crec.ifas.ufl. pomegranates, que contiene información más detallada sobre la botánica de la granada, el cultivo, los cultivares, los viveros, las asociaciones de los productores y más información. Aquellos interesados en aprender más sobre las granadas en Florida se les invita a visitar este sitio web.

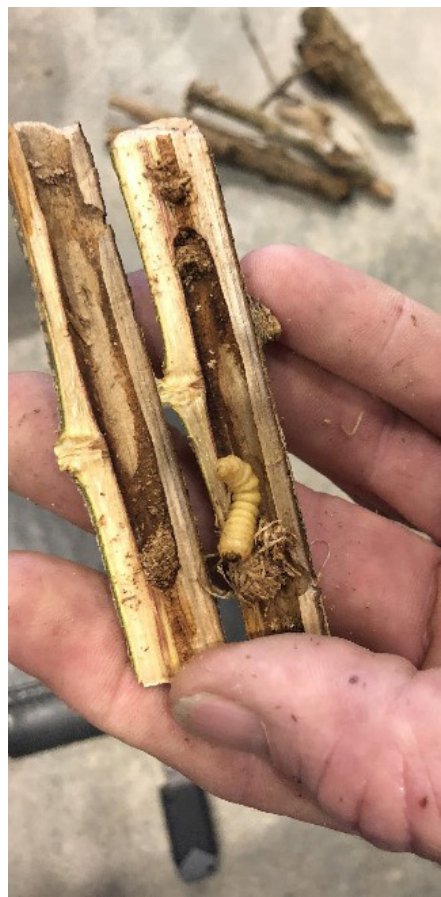

Figura 17. Daño del barrenador de cabeza plana al árbol de granada en Cross City en FL.

Crédito: A. Sarkhosh, UF/IFAS

\section{Referencias}

Holland. D., Hatib. K., Bar-Yảakov. I. (2009). "Pomegranate: botany, horticulture, breeding." Horticultural Review 35: 127-191

Sarkhosh, A., Zamani, Z., Fatahi, R., Sayyari, M. (2009). "Antioxidant activity, total phenols, anthocyanin, ascorbic acid content and woody portion index (wpi) in Iranian Soft-Seed pomegranate Fruits." Global Science Books. Food 1: 68-72.

Sarkhosh, A., Zamani, Z., Fatahi, R., Ranjbar, H., Vazifeshenas, M.R. (2008). "Evaluation of Iranian soft-seed pomegranate accessions by using simple and multivariate analysis methods." Tree and Forestry Science and Biotechnology 2: 18-25.

Zamani, Z., Sarkhosh, A., Fatahi, R., Ebadi, A. (2007). "Genetic relationships among pomegranate genotypes studied by fruit characteristics and RAPD markers." The Journal of Horticulture Science \& Biotechnology 82: 11-18. 